\title{
HPLC and chemometrics-assisted spectroscopic methods used for determination of dissolution of paracetamol and orphenadrine citrate in a combination tablet
}

\author{
Suttikan Sonchai ${ }^{1}$, Chutima Phechkrajang2, Piyanuch Rojsanga ${ }^{2 *}$ \\ 1 Center of Analysis for Product Quality, Faculty of Pharmacy, Bangkok, Thailand \\ 2 Department of Pharmaceutical Chemistry, Faculty of Pharmacy, Mahidol University, Bangkok, Thailand
}

\begin{abstract}
Simultaneous determination of paracetamol and orphenadrine citrate by high-performance liquid chromatographic (HPLC) and chemometric-assisted spectroscopic methods are described. The HPLC method was based on RP C18 column $(5 \mu \mathrm{m}, 4.6 \mathrm{~mm} \times 150 \mathrm{~mm})$ using monobasic ammonium phosphate, methanol, and acetonitrile $(400: 450: 150 \mathrm{v} / \mathrm{v} / \mathrm{v})$ as a mobile phase. The flow rate was set at $1.5 \mathrm{~mL} / \mathrm{min}$ with column temperature at $40^{\circ} \mathrm{C}$ and UV detection at $215 \mathrm{~nm}$. Paracetamol and orphenadrine citrate were separated within 7 mins by an isocratic elution. Good linearities were obtained in concentration ranges of $5-150 \mu \mathrm{g} / \mathrm{mL}$ for paracetamol and $0.8-12 \mu \mathrm{g} / \mathrm{mL}$ for orphenadrine citrate, with correlation coefficients (r) $>0.99$. Recovery of the analytical method was acceptable (102.8-104.8\% for paracetamol and 92.4-102.3\% for orphenadrine citrate). Relative standard deviations (RSDs) of repeatability and intermediate precision were less than $2.0 \%$. Likewise, the resolution has been completed by using partial least square regression applying UV spectrum. The successive partial least squares regression (PLSR) methods were used with UV spectra data of 200-400 $\mathrm{nm}$ and 5 latent factors for paracetamol and orphenadrine citrate. Finally, the developed methods proved to be suitable to assay the dissolution samples of paracetamol and orphenadrine citrate in the combination tablet.
\end{abstract}

\section{Keywords:}

Paracetamol, Orphenadrine, HPLC-PDA, Partial least squares regression, Multicomponent analysis

\section{INTRODUCTION}

Paracetamol (4-acetamidophenol) is an effective analgesic and antipyretic for treatment of minor, noninflammatory conditions ${ }^{1}$. Orphenadrine citrate ((RS)(dimethyl-2-(2-methylbenz-hydroxy) ethyl) amine citrate) is employed as skeletal muscle relaxant ${ }^{2}$. Thus, tablets containing paracetamol (PAR) and orphenadrine citrate (OPC) show combined analgesic, antipyretic and skeletal muscle relaxing actions. The structures of PAR and OPC are displayed in Figure 1.

Many analytical methods have been reported on the estimation of paracetamol and orphenadrine citrate either separately or in combination with other drugs in pharmaceutical dosage forms or biological fluids ${ }^{3-9}$. However, only RP-HPLC ${ }^{8}$, and spectrophotometric ${ }^{10}$ methods have been described in the literature for the simultaneous determination of PAR and OPC in their combined formulations, despite the recognized commercial distribution of their tablets. Moreover, there is no official method for dissolution testing of their combined formulations. To assay the dissolution samples of drug products, a straightforward but broadly relevant analytical method is always preferred. Apparently, PAR and OPC fixed combination tablet considered to be an analytically challenging mixture, from the spectrophotometric viewpoint. This is ascribed not only to the large difference in ratios between PAR and ORP, which exceeds 1:12, respectively, but also the spectral overlap of both drugs. Consequently, analysis of PAR and OPC could not be performed concurrently by direct UV spectrophotometry without separation.

\section{*Corresponding author:}

*Piyanuch Rojsanga piyanuch.roj@mahidol.ac.th 

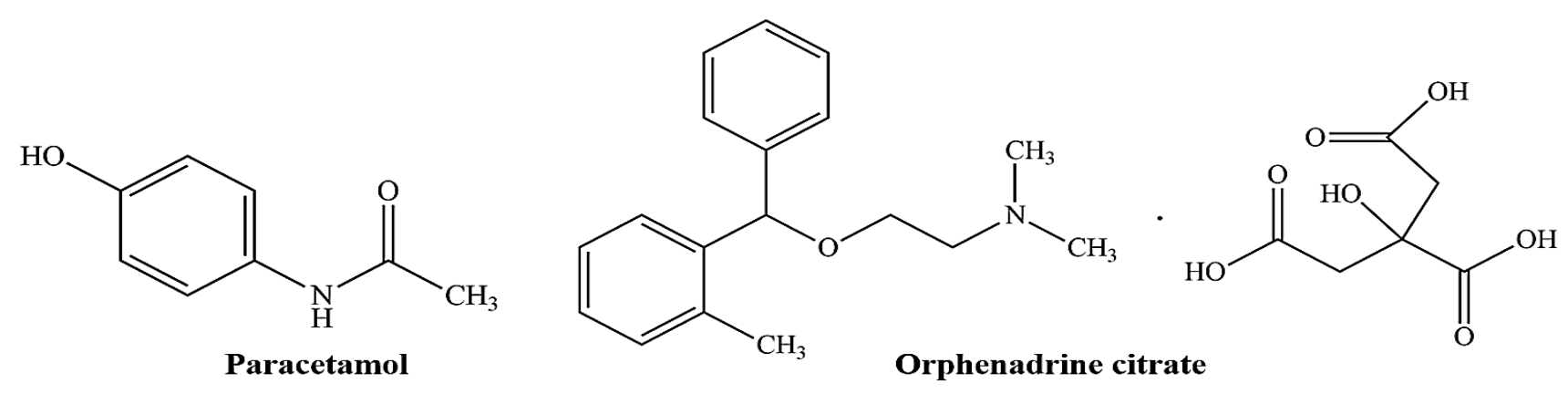

Figure 1. Chemical structure of Paracetamol and Orphenadrine citrate.

Application of chemometric approach with spectrophotometric data may overcome this restriction. Multivariate calibration is a chemometric method which has been utilized for determination of drugs in combination dosage forms including tablets ${ }^{11-13}$.

In this study, chemometric-assisted spectrophotometry using partial least squares regression (PLSR) was developed to analyze the dissolution sample of PAR and OPC in combination tablet. In addition, a simple high-performance liquid chromatography (HPLC) was developed and validated to use as a reference method for chemometric method.

\section{MATERIALS AND METHODS}

\subsection{Instruments and software}

The analysis was carried out using HPLC system; a Shimadzu LC-10 system (Shimadzu, Kyoto, Japan) equipped with a model series LC-10 ADVP pump, SCL-10 AVP system controller, DGU-12A degasser, SIL-10ADVP auto injector, and a SPD-M20A diode array detector. A dual beam Shimadzu (Kyoto/Japan) UV-Vis. spectrophotometer, model 1650 UV-PC. The utilized software was UV-Probe personal spectroscopy software version 2.71 (SHIMADZU). Drugs' dissolution was tested using a ERWEKA DT 720 (Germany) equipped with standard USP type-II paddle.

\subsection{Chemicals, reagents, and pharmaceutical formu- lation}

All chemicals were of analytical-reagent grade. HPLC grade methanol and acetonitrile (Merk, Darmstadt, Germany) and deionized water were used for preparing mobile phase solutions. The standards for Paracetamol (PAR) and Orphenadrine citrate (OPC) were kindly supplied by Defense Pharmaceutical Factory, Bangkok, Thailand. The purity was found to be $100.0 \pm 0.1 \%$ and $100.1 \pm 0.2 \%$ for PAR and ORP, respectively, using the current compendial HPLC method of each drug ${ }^{14,15}$. ORPHETAMOL ${ }^{\circledR}$ tablets, manufactured by Defense Pharmaceutical Factory (DPF), Bangkok, Thailand, is labeled to contain paracetamol $450 \mathrm{mg}$ and orphenadrine citrate $35 \mathrm{mg}$ per tablet.

\subsection{High-performance liquid chromatographic method}

\subsubsection{Chromatographic condition}

The chromatographic separation was performed on a column C18, Hypersil GOLD ${ }^{\circledR}, 5 \mu \mathrm{m}, 4.6 \times 150 \mathrm{~mm}$ i.d., (Thermo, USA) with the column temperature maintained at $40^{\circ} \mathrm{C}$. The mobile phase was obtained by mixing $0.05 \mathrm{M}$ monobasic ammonium phosphate $\mathrm{pH}$ 7.9: methanol: acetonitrile $(400: 450: 150(\mathrm{v} / \mathrm{v} / \mathrm{v}))$, delivered at a flow rate of $1.5 \mathrm{~mL} / \mathrm{min}$ and detected by ultraviolet at $215 \mathrm{~nm}$

\subsubsection{Solutions}

Standard stock solutions of PAR and OPC in mobile phase were separately prepared in concentration of $12.5 \mathrm{mg} / \mathrm{mL}$ and $1 \mathrm{mg} / \mathrm{mL}$, respectively. One milliliter of each stock solution was transferred to a $50 \mathrm{~mL}$ volumetric flask and adjusted with mobile phase to obtain PAR and OPC in concentration of $250 \mu \mathrm{g} / \mathrm{mL}$ and $20 \mu \mathrm{g} / \mathrm{mL}$, respectively. The working standard mixtures were prepared at concentration levels of $5-150 \mu \mathrm{g} / \mathrm{mL}$ and $0.2-12 \mu \mathrm{g} / \mathrm{mL}$ for PAR and OPC, respectively.

For placebo solution, $96 \mathrm{mg}$ powdered placebo was weighed and introduced in a vessel of dissolution apparatus containing $900 \mathrm{~mL}$ of distilled water, thermostatically controlled at $37 \pm 0.5^{\circ} \mathrm{C}$. A vessel content was agitated using a paddle at a rate of $50 \mathrm{rpm}$. for $60 \mathrm{~min}$.

Sample solutions prepared for recovery study were in levels of $50 \%$ (50 $\mu \mathrm{g} / \mathrm{mL}$ PAR, $4 \mu \mathrm{g} / \mathrm{mL}$ OPC), $100 \%(100 \mu \mathrm{g} / \mathrm{mL}$ PAR, $8 \mu \mathrm{g} / \mathrm{mL}$ OPC), $150 \%$ (150 $\mu \mathrm{g} / \mathrm{mL}$ PAR, $12 \mu \mathrm{g} / \mathrm{mL}$ ). Related amount of PAR, OPC each level with $96 \mathrm{mg}$ placebo was weighed and placed in a vessel of dissolution apparatus containing $900 \mathrm{~mL}$

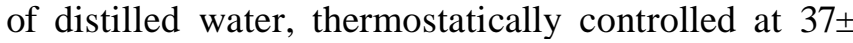
$0.5^{\circ} \mathrm{C}$. A vessel content was agitated using a paddle at a rate of $50 \mathrm{rpm}$. for $60 \mathrm{~min}$.

The placebo and sample solutions were withdrawn from the dissolution medium and filtered. 
Two milliliters of each filtrate were transferred to 50$\mathrm{mL}$ volumetric flask and adjust to volume by mobile phase. All solutions were passed through a polytetrafluoroethylene (PTFE) syringe filter prior to injection.

\subsubsection{Validation of HPLC method}

The proposed HPLC method was validated in term of specificity, linearity, range, accuracy, precision, and system suitability according to the International Council for Harmonization (ICH) ${ }^{16}$. For specificity, the chromatograms of mobile phase, distilled water, standard solution, and sample solution taken from dissolution study were compared. The linearity was assessed by analyzing the series of working standard mixtures in mobile phase. Six concentration levels in the range of $5-150 \mu \mathrm{g} / \mathrm{mL}$ and $0.2-12 \mu \mathrm{g} / \mathrm{mL}$ for PAR and OPC, respectively, were prepared. A regression equation of the calibration curve was calculated using least-square linear regression (correlation coefficient $(r) \geq 0.990)$. The accuracy was operated as described in sample solution preparation at levels of 50\% (3 samples), 100\% (3 samples) and $150 \%$ (3 samples). Recovered amount of PAR and OPC were calculated in relation to the added amount, whereas the acceptance criteria for recovery was $95-105 \%$. In the precision study, repeatability and intermediate precision were carried out by analyzing 6 sample solution preparation at level of $100 \%$ on the same day $(n=6)$ and 2 different analysts $(n=12)$, respectively. The acceptance criterion for RSD was $\leq 2.0 \%$. System suitability was determined from 5 replicate injections of the system suitability standard $(40 \mu \mathrm{g} / \mathrm{mL}$ PAR and $8 \mu \mathrm{g} / \mathrm{mL}$ OPC) before sample analyses. The acceptance criteria were; number of theoretical plates $(\mathrm{N})>1500$, tailing factor $<2$ and $\% \mathrm{RSD} \leq 2.0$ for peak area.

Table 1. Composition of calibration set samples.

\begin{tabular}{|c|c|c|c|c|c|}
\hline Calibration sample & PAR $(\mu \mathrm{g} / \mathrm{mL})$ & OPC $(\mu \mathrm{g} / \mathrm{mL})$ & Calibration sample & $\operatorname{PAR}(\mu \mathrm{g} / \mathrm{mL})$ & OPC $(\mu \mathrm{g} / \mathrm{mL})$ \\
\hline 1 & 39.1 & 14.8 & 25 & 19.5 & 7.4 \\
\hline 2 & 57.7 & 14.3 & 26 & 28.9 & 7.1 \\
\hline 3 & 49.8 & 2.8 & 27 & 24.9 & 1.4 \\
\hline 4 & 48.5 & 27.2 & 28 & 24.2 & 13.6 \\
\hline 5 & 46.4 & 9.3 & 29 & 23.2 & 4.6 \\
\hline 6 & 54.1 & 9.4 & 30 & 27.0 & 4.7 \\
\hline 7 & 55.6 & 25.5 & 31 & 27.8 & 12.8 \\
\hline 8 & 45.6 & 25.6 & 32 & 22.8 & 12.8 \\
\hline 9 & 49.6 & 15.9 & 33 & 22.5 & 7.8 \\
\hline 10 & 47.5 & 15.7 & 34 & 24.8 & 8.0 \\
\hline 11 & 48.6 & 15.0 & 35 & 23.8 & 7.8 \\
\hline 12 & 48.6 & 0.0 & 36 & 24.3 & 7.5 \\
\hline 13 & 49.1 & 0.0 & 37 & 24.3 & 0.0 \\
\hline 14 & 9.2 & 14.9 & 38 & 24.6 & 0.0 \\
\hline 15 & 60.6 & 27.5 & 39 & 4.5 & 7.3 \\
\hline 16 & 61.9 & 28.4 & 40 & 31.0 & 14.2 \\
\hline 17 & 59.7 & 28.5 & 41 & 29.8 & 14.2 \\
\hline 18 & 61.9 & 28.8 & 42 & 24.7 & 7.0 \\
\hline 19 & 49.9 & 14.0 & 43 & 24.9 & 6.9 \\
\hline 20 & 49.4 & 13.8 & 44 & 19.1 & 0.0 \\
\hline 21 & 38.8 & 0.0 & 45 & 29.8 & 2.7 \\
\hline 22 & 38.3 & 0.0 & 46 & 29.5 & 2.8 \\
\hline 23 & 39.0 & 0.0 & 47 & 29.5 & 2.7 \\
\hline 24 & 38.7 & 0.0 & 48 & 29.3 & 2.7 \\
\hline
\end{tabular}

Table 2. Composition of test set samples.

\begin{tabular}{|c|c|c|c|c|c|}
\hline Test sample & $\operatorname{PAR}(\mu \mathrm{g} / \mathrm{mL})$ & OPC $(\mu \mathrm{g} / \mathrm{mL})$ & Test sample & $\operatorname{PAR}(\mu \mathrm{g} / \mathrm{mL})$ & OPC $(\mu \mathrm{g} / \mathrm{mL})$ \\
\hline 1 & 9.0 & 14.7 & 13 & 29.5 & 2.8 \\
\hline 2 & 49.4 & 14.1 & 14 & 29.6 & 2.8 \\
\hline 3 & 49.9 & 13.8 & 15 & 29.8 & 2.8 \\
\hline 4 & 4.6 & 7.4 & 16 & 29.2 & 2.7 \\
\hline 5 & 30.3 & 13.8 & 17 & 29.2 & 2.8 \\
\hline 6 & 30.9 & 14.4 & 18 & 43.5 & 2.8 \\
\hline 7 & 24.9 & 7.0 & 19 & 44.1 & 2.9 \\
\hline 8 & 24.7 & 6.9 & 20 & 43.3 & 2.9 \\
\hline 9 & 19.4 & 0.0 & 21 & 43.7 & 2.9 \\
\hline 10 & 19.5 & 0.0 & 22 & 43.2 & 2.9 \\
\hline 11 & 19.4 & 0.0 & 23 & 42.8 & 2.9 \\
\hline 12 & 29.2 & 2.8 & - & - & - \\
\hline
\end{tabular}




\subsection{Chemometric method}

\subsubsection{Spectrophotometric condition}

The calibration set and test set samples were recorded for their UV absorption data between 200-400 $\mathrm{nm}$ at $0.5 \mathrm{~nm}$ intervals using $1-\mathrm{cm}$ quartz cells. The Unscrambler 9.6 (Camo, Norway) was employed for PLSR models construction.

Working standards solutions concentration of $250 \mu \mathrm{g} / \mathrm{mL}$ of PAR and $125 \mu \mathrm{g} / \mathrm{mL}$ OPC were prepared by accurately weighing the working standard by analytical balance and diluted to the desired concentration with deionized water. These working solutions were used to prepare calibration set and test set samples as shown in Table 1 and Table 2.

The models with the lowest relative standard error of prediction (RSEP) were selected as the optimum models. equation.

RSEP was calculated by using the following

$$
\operatorname{PRSE}(\%)=100 \sqrt{\frac{\sum_{i=1}^{m}\left(\boldsymbol{y}_{\text {pred }}-\boldsymbol{y}_{\text {ref }}\right)^{2}}{m}}
$$

Where $\mathrm{m}$ is the number of samples used, $\mathrm{y}_{\text {ref }}$ is the true value and $y_{\text {pred }}$ is the predicted value of a test set sample.

\subsubsection{Validation of chemometric method}

The optimum PLSR models were internal validated by cross-validation and external validated by determination of test set samples those were not contributed to models construction and compared with HPLC results. The comparison was expressed as the correlation plot of the results from PLSR model (y-axis) and HPLC method (x-axis). The correlation coefficient closes to 1.0 indicating the agreement of the results of two methods and imply to the accuracy of chemometric model.

\subsection{Assay of dissolution solutions}

An eight-vessel dissolution apparatus containing $900 \mathrm{~mL}$ of distilled water, thermostatically controlled at $37 \pm 0.5^{\circ} \mathrm{C}$ was used, the tablet was introduced into the paddle using a rate of $50 \mathrm{rpm}$. Samples were withdrawn from the dissolution medium after $60 \mathrm{~min}$ and filtered. Two milliliters of the filtrate were transferred to $50-\mathrm{mL}$ volumetric flask and adjust to volume by either mobile phase for HPLC method or distilled water for chemometric method.

\section{RESULTS AND DISCUSSION \\ 3. RESULTS AND DISCUSSION}


Pharmaceutical Sciences Asia

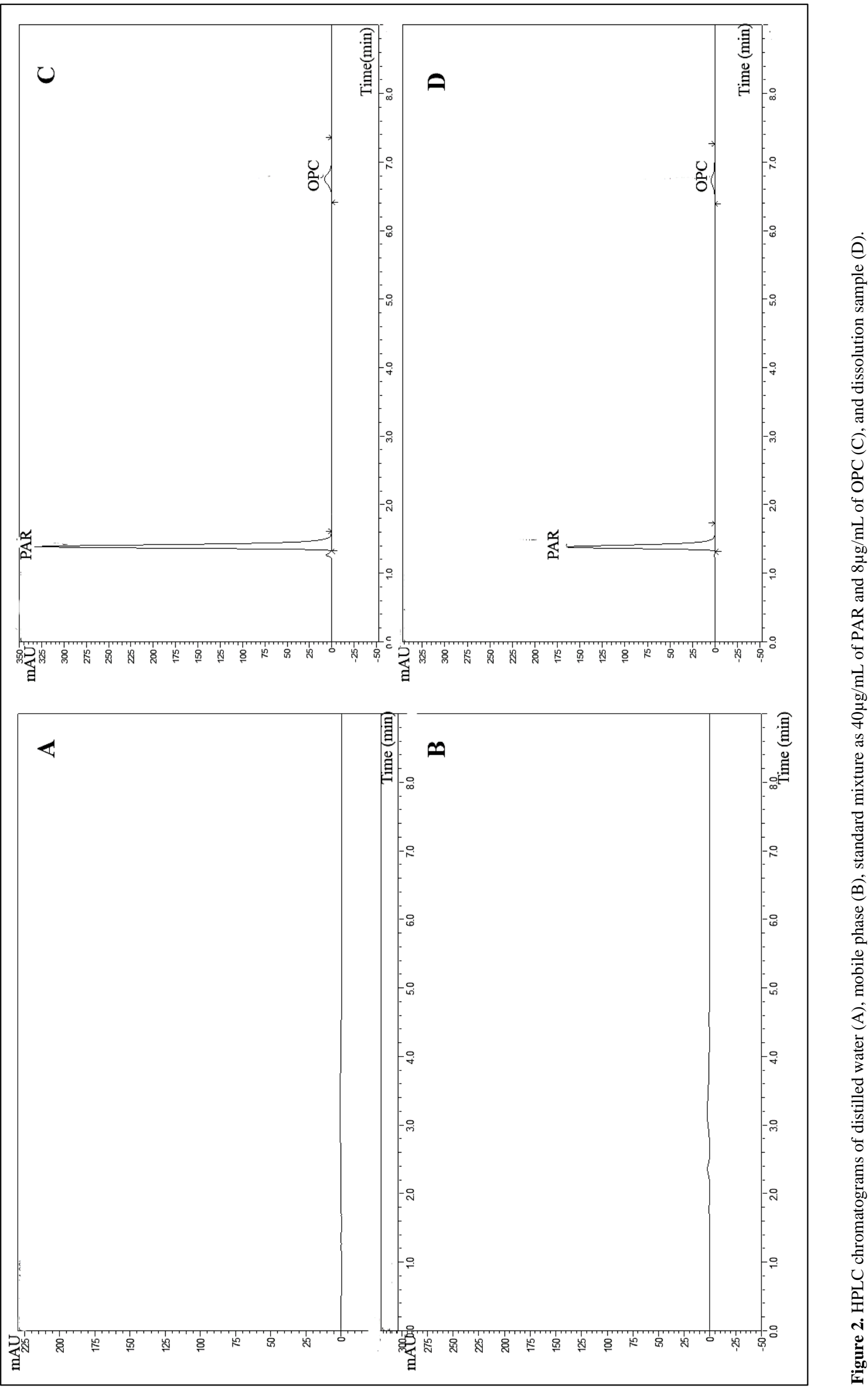


Table 3. Method validation data of PAR and OPC by the optimized HPLC method.

\begin{tabular}{|c|c|c|c|c|}
\hline Validation & meter & Acceptance criteria & PAR & OPC \\
\hline \multicolumn{2}{|l|}{ Linearity } & $\mathrm{r} \geq 0.99$ & $\begin{array}{l}y=12,614 x+3,586.5 \\
r=0.9999\end{array}$ & $\begin{array}{l}y=12,684 x-1,357.1 \\
r=0.9997\end{array}$ \\
\hline \multicolumn{2}{|l|}{ Range } & & $5-150 \mu \mathrm{g} / \mathrm{mL}$ & $0.2-12 \mu \mathrm{g} / \mathrm{mL}$ \\
\hline \multicolumn{2}{|l|}{ Accuracy $(\% \mathrm{R})$} & $92-105 \%$ & $102.8-104.7 \%$ & $93.4-102.3 \%$ \\
\hline \multicolumn{2}{|c|}{ Repeatability (\%RSD, n=6) } & $2.0 \%$ & $0.78-1.35$ & $0.82-1.14$ \\
\hline \multicolumn{2}{|c|}{ Intermediate precision $(\% \mathrm{RSD}, \mathrm{n}=12)$} & $2.0 \%$ & 0.89 & 0.97 \\
\hline \multirow{3}{*}{ System suitability } & Plates & $>1500$ & $>2338$ & $>6826$ \\
\hline & Tailing & $<2.0$ & $<1.6$ & $<1.1$ \\
\hline & $\%$ RSD & $<2.0$ & 0.74 & 0.33 \\
\hline
\end{tabular}

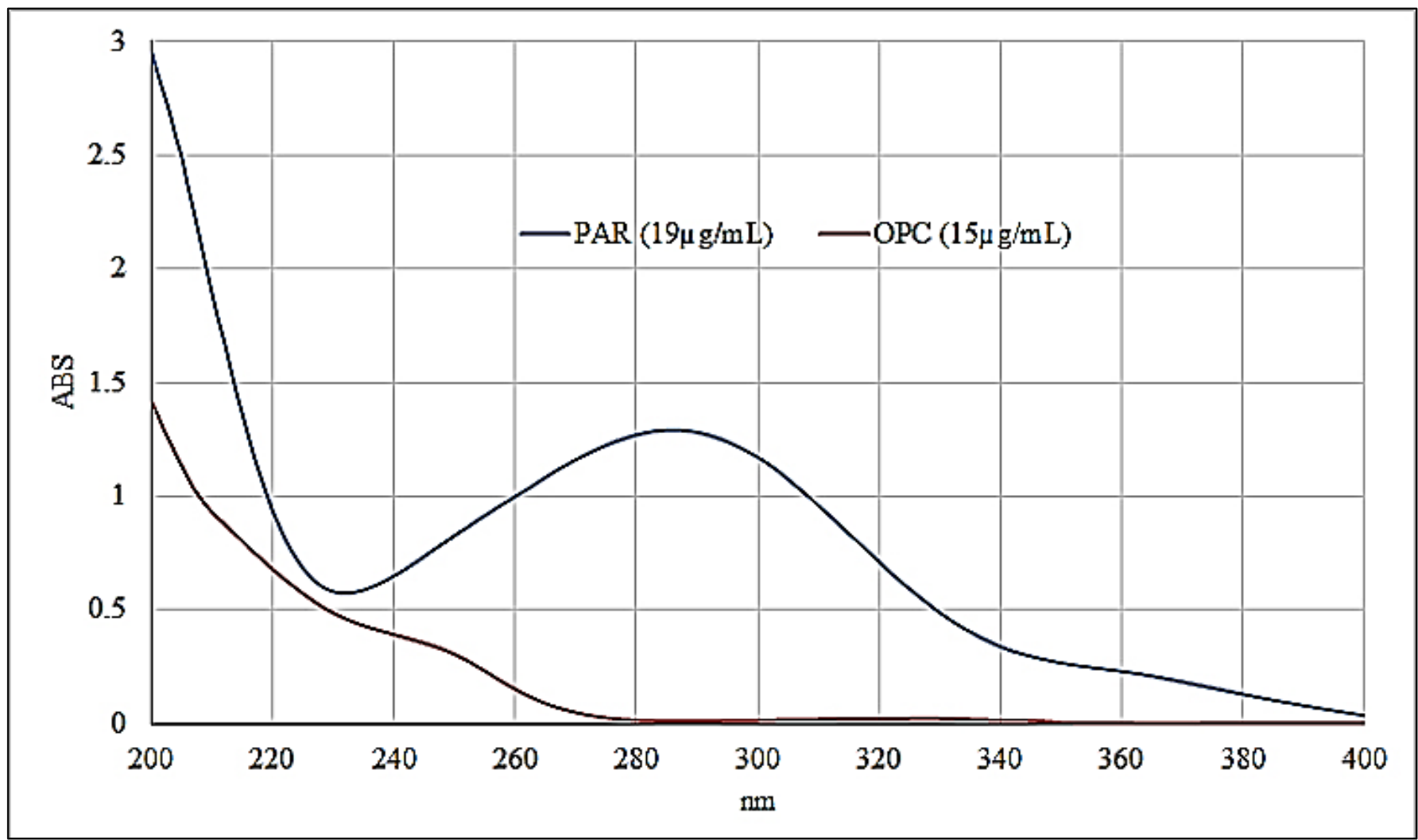

Figure 3. UV spectra of PAR $(19 \mu \mathrm{g} / \mathrm{mL})$ and OPC $(15 \mu \mathrm{g} / \mathrm{mL})$.

\subsection{Development of Chemometric method}

UV spectrophotometry is generally allowed for quantitative determination of an active pharmaceutical ingredient with high purity. Direct determination of combination drugs by UV spectrophotometer is usually limited from the overlapping of their UV spectra. Several efforts were tried to overcome this limitation including first derivative and higher order UV spectra, mean centering of ratio spectra. The main problem of this study is that the concentration of OPC in tablet is very low, compares with PAR. The tablet formula in Thailand contains $35 \mathrm{mg}$ of OPC and $450 \mathrm{mg}$ of PAR per tablet. As shown in Figure 3, UV spectra of PAR and OPC are completely overlapped in UV region. And unfortunately, the molar absorptivity of PAR and OPC are quite different. As seen in Figure 3, UV absorbance of $19 \mu \mathrm{g} / \mathrm{mL}$ of PAR is dominated and covered absorbance signal of $15 \mu \mathrm{g} / \mathrm{mL}$ of OPC. Therefore, simultaneous quantitative determination of OPC and PAR with indirect UV spectrophotometric techniques as described above were not success. In this study, partial least square regression (PLSR), a widely used chemometric technique, was tried for determination of OPC and PAR in dissolution samples. The success PLSR model for determination of PAR and OPC were performed by using UV absorption data between $200-400 \mathrm{~nm}$ with 5 latent factors. The parameters of OPC and PAR optimum PLSR models are showed in Table 4.

\subsection{Validation of chemometric method}

The internal validation of PLSR models were cross-validation. The results of cross-validation of the successive PLSR models were displayed as the plot between actual concentrations and predicted concen- 
trations of the samples in the calibration set (Figure 4). The slope and correlation coefficient $\left(\mathrm{R}^{2}\right)$ close to 1.0 indicating the agreement of actual and predicted concentrations and assure the future application. The developed PLSR models were external validated by quantitation of test set samples. The determination results were expressed by the plot between actual concentrations and predicted concentrations of the samples in the test set (Figure 5). RSEP of the optimum models were calculated, the minimum RSEP indicating the accuracy and precision of the model. As shown in Figure 4 and Figure 5, the slope of the plots was around $1(0.9978$ for PAR and 0.9980 for OPC) and the $\mathrm{R}^{2}$ values were higher than 0.99. The RSEP values, as shown in Table 5, were less than $6 \%$. These results indicated that the PLSR models for OPC and PAR were accurate and suitable for intend purpose.

\subsubsection{Assay of dissolution solutions}

Dissolution solutions of six combined tablets performing under USP condition of OPC in the combination tablets ${ }^{17}$ were taken and assayed by the developed HPLC method and PLSR models. The assay results as quantity percent $(\% \mathrm{Q})$ of HPLC and PLSR models were compared using $t$-test at $95 \%$ confidence level. There was no significant difference $(P$-values $>0.05)$ between the results as indicated in Table 5 .
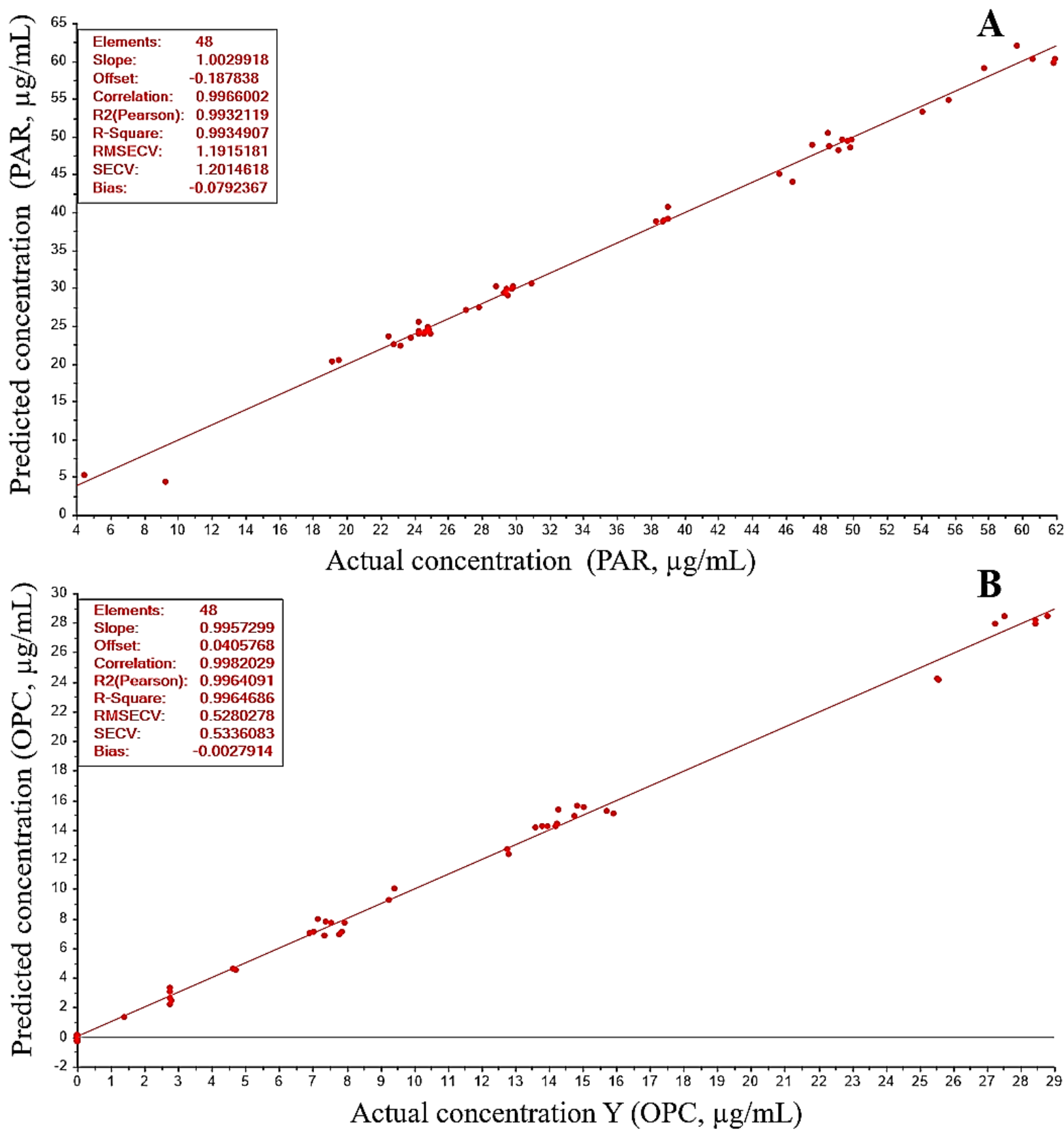

Figure 4. The cross-validation plots of (A) PAR and (B) OPC. 


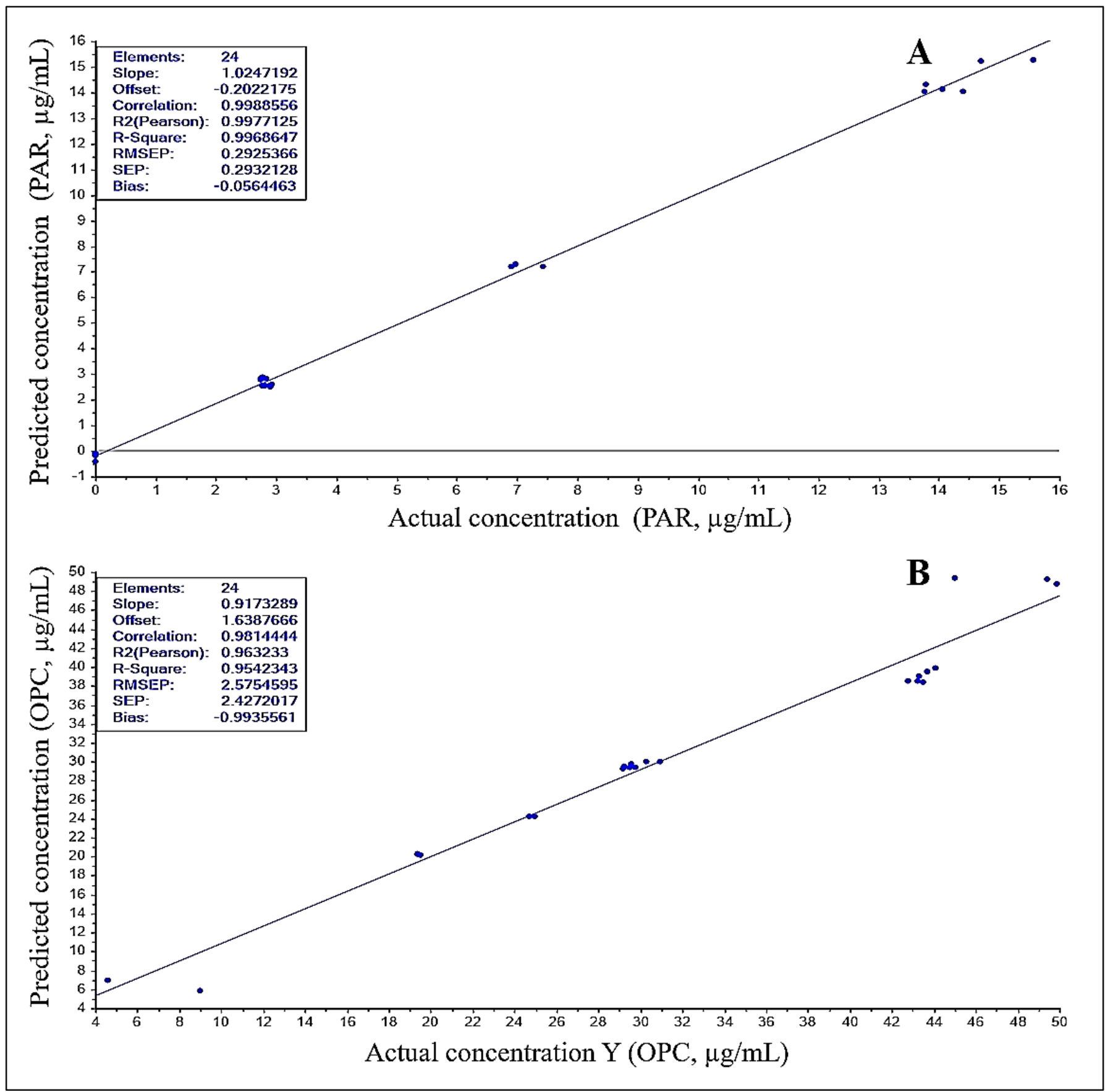

Figure 5. The correlation plots between actual and predicted concentrations of test set samples for (A) PAR and (B) OPC.

Table 4. The parameters for PAR and OPC of optimum PLSR models.

\begin{tabular}{lcc}
\hline \multicolumn{1}{c}{ Model Parameters } & PAR & OPC \\
\hline Wavelength (nm) & $200-400$ & $200-400$ \\
Latent factors & 5 & 5 \\
Calibration & - & - \\
Slope & 0.9978 & 0.9980 \\
Offset & 0.0796 & 0.0201 \\
$\mathrm{R}^{2}$ & 0.9978 & 0.9980 \\
Cross-validation & - & - \\
Slope & 0.9940 & 0.9957 \\
Offset & 0.2163 & 0.0406 \\
$\mathrm{R}^{2}$ & 0.9960 & 0.9965 \\
RSEP (\%) & 5.96 & 3.98 \\
\hline
\end{tabular}


Table 5. The comparison of \%Q obtained from HPLC and PLSR methods.

\begin{tabular}{cccccc}
\hline Tablet number & \multicolumn{2}{c}{ PAR } & & OPC \\
\cline { 2 - 6 } & HPLC & PLSR & HPLC & PLSR \\
\hline 1 & 96.7 & 96.0 & 80.4 & 81.6 \\
2 & 98.0 & 99.8 & 83.3 & 83.1 \\
3 & 96.1 & 97.6 & 81.6 & 82.8 \\
4 & 97.0 & 98.8 & 82.6 & 81.2 \\
5 & 95.9 & & 96.4 & 82.5 & 82.5 \\
6 -values & 95.1 & & 96.4 & & 0.63 \\
\hline
\end{tabular}

\section{CONCLUSIONS}

The HPLC and chemometric-assisted spectrophotometric methods have been proposed and successfully applied for the simultaneous determination of PAR and OPC. The dissolution results obtained by chemometric method were found to be in good agreement with that of HPLC method with the percentage release of all two drugs were above $80 \%$ in $60 \mathrm{~min}$. The HPLC method is more specific than the chemometric-assisted spectrophotometric method, but it requires costly equipment and materials, for example, columns and HPLC grade solvents. Chemometric method is less expensive and does not need complicated instrumentation and any separation steps. The proposed HPLC and PLSR methods were found to be suitable and can be effectively used to assay the dissolution samples of PAR and OPC in fixed dose combination tablet.

\section{ACKNOWLEDGEMENT}

The authors acknowledge Defense Pharmaceutical Factory to provide samples and placebo under study.

\section{Conflict of interest}

The authors wish to confirm that there are no known conflicts of interest related with this publication.

\section{Funding}

None to declare.

\section{Ethics approval}

None to declare.

\section{Article info:}

Received February 2, 2021

Received in revised form May 9, 2021

Accepted May 10, 2021

\section{REFERENCES}

1. Chandrasekharan NV, Dai H, Roos KL, Evanson NK, Tomsik J, Elton TS, et al. COX-3, a cyclooxygenase-1 variant inhibited by acetaminophen and other analgesic/antipyretic drugs: cloning, structure, and expression. Proc Natl Acad Sci U S A. 2002;99(21): 13926-31.

2. Stanko JR. Review of oral skeletal muscle relaxants for the craniomandibular disorder (CMD) practitioner. Cranio. 1990; 8(3):234-43.

3. Yehia AM, Abd El-Rahman MK. Application of normalized spectra in resolving a challenging Orphenadrine and Paracetamol binary mixture. Spectrochim Acta A Mol Biomol Spectrosc. 2015;138:21-30.

4. Erk N, Ozkan Y, Banoglu E, Ozkan SA, Senturk Z. Simultaneous determination of paracetamol and methocarbamol in tablets by ratio spectra derivative spectrophotometry and LC. J Pharm Biomed Anal. 2001;24(3):469-75.

5. Sebaiy MM, El-Adl SM, Mattar AA. Different techniques for overlapped UV spectra resolution of some co-administered drugs with paracetamol in their combined pharmaceutical dosage forms. Spectrochim Acta A Mol Biomol Spectrosc. 2020;224: 117429.

6. Lourencao BC, Medeiros RA, Rocha-Filho RC, Mazo LH, Fatibello-Filho O. Simultaneous voltammetric determination of paracetamol and caffeine in pharmaceutical formulations using a boron-doped diamond electrode. Talanta. 2009;78(3):748-52.

7. Haj-Ali DN, Hamdan, II. Development of a capillary electrophoresis method for the determination of orphenadrine citrate in tablets in the presence of paracetamol. Saudi Pharm J. 2010; 18(4):233-7.

8. Arayne MS, Sultana N, Siddiqui FA. Simultaneous Determination of Paracetamol and Orphenadrine Citrate in Dosage Formulations and in Human Serum by RP-HPLC. J Chin Chem Soc-Taip. 2009;56(1):169-74.

9. Boltia SA, Soudi AT, Elzanfaly ES, Zaazaa HE. Development and Validation of Chromatographic Methods for Simultaneous Determination of Paracetamol, Orphenadrine Citrate and Caffeine in Presence of P-aminophenol; Quantification of P-aminophenol Nephrotoxic Impurity Using LC-MS/MS. J Chromatogr Sci. 2020;58(3):223-33.

10. Sratthaphut L, Ruangwises N. Determination of paracetamol and orphenadrine citrate in pharmaceutical tablets by modeling of spectrophotometric data using partial least-squares and artificial neural networks. Yakugaku Zasshi. 2007;127(10):1723-9.

11. Palur K, Archakam SC, Koganti B. Chemometric assisted UV spectrophotometric and RP-HPLC methods for simultaneous determination of paracetamol, diphenhydramine, caffeine and phenylephrine in tablet dosage form. Spectrochim Acta A Mol Biomol Spectrosc. 2020;243:118801.

12. Devi Singh V, Kumar Singh V. Chemometric assisted UVspectrophotometric methods for simultaneous estimation of Darunavir ethanolate and Cobicistat in binary mixture and their tablet formulation. Spectrochim Acta A Mol Biomol Spectrosc. 2021;250:119383.

13. Medendorp J, Colon I, Ryan T. Multivariate approaches for the development of quality control in-situ fiber optics dissolution methods for fixed-dose combination tablets. Drug Dev Ind Pharm. 2019;45(6):999-1008.

14. The United States pharmacopeia 43. Acetaminophen. National formulary 38, Volume 1. Rockville (MD): United States Pharmacopeial Convention; 2021. p. 38.

15. The United States pharmacopeia 43. Orphenadrine Citrate. 
National formulary 38, Volume 1. Rockville (MD): United States Pharmacopeial Convention; 2021. p. 328.

16. International Conference on Harmonisation. ICH Q2(R1) Validation of analytical procedures:text and methodology [document on the Internet]. Geneva; November 2005 Available from: https:// www.ich.org/page/quality-guidelines.

17. The United States pharmacopeia 43. Orphenadrine Citrate, Aspirin, and Caffeine Tablets. National formulary 38, Volume 2. Rockville (MD): United States Pharmacopeial Convention; 2021. p. 3288. 